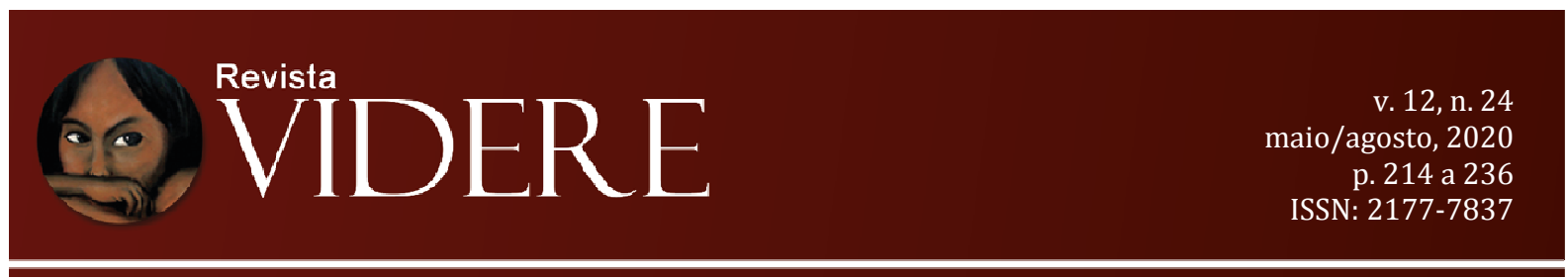

\title{
CABE AO ESTADO CENSURAR AS TENTAÇÕES DE CRISTO?: considerações sobre a (im)possibilidade de exclusão de conteúdos no meio digital a partir do caso Porta dos Fundos e Netflix
}

\author{
IS IT FOR THE STATE TO CENSOR CHRIST'S TEMPTATIONS?: \\ considerations about the (im)possibility of excluding content in the digital \\ medium from the perspective of the Porta dos Fundos and Netflix Case
}

Ulisses Levy Silvério dos Reis Doutor em Direito pela Universidade Federal do Ceará (UFC), Brasil Professor da Universidade Federal Rural

Semiárido (UNIFERSA), Brasil

E-mail: ulisses.reis@ufersa.edu.br

OrcID: https://orcid.org/0000-0003-1476-416X

\begin{abstract}
RESUMO: Este trabalho tem por objeto a tutela do direito fundamental à liberdade de expressão no conflito envolvendo o canal Porta dos Fundos e a empresa de streaming Netflix, surgido a partir de representação judicial promovida por associação religiosa junto ao Tribunal de Justiça do Rio de Janeiro. A segunda instância do Judiciário local, com base na necessidade de proteger valores considerados sagrados por parte da população brasileira, determinou a exclusão do material artístico veiculado pelas empresas citadas. A pesquisa problematiza se a tutela judicial havida no caso concreto é compatível com os parâmetros definidos pelo sistema interamericano de direitos humanos em relação à restrição lícita da liberdade de expressão, os quais vinculam o Estado brasileiro. A investigação foi realizada com o método dedutivo e a partir de fontes documentais e bibliográficas, com ênfase em decisões e relatórios da Corte e da Comissão Interamericanas. O desenvolvimento do trabalho divide-se em duas partes: primeiro analisou-se os aspectos fático-jurídicos do conflito concreto e depois investigou-se os parâmetros que definem a liberdade de expressão no sistema interamericano. Concluiu-se que a decisão do órgão judiciário local contrariou as determinações regionais em matéria de proteção dos direitos humanos.
\end{abstract}

PALAVRAS-CHAVE: Direitos fundamentais. Liberdade de expressão. Censura. Supremo Tribunal Federal. Sistema interamericano de direitos humanos.

ABSTRACT: This work focus on the protection of the fundamental right to freedom of expression in the conflict involving the Porta dos Fundos channel and the streaming company Netflix, arising from a judicial representation promoted by a religious association before the State Court of Justice of the Rio de Janeiro. The second instance of the local Judiciary, based on the need to protect values considered sacred by the Brazilian population, determined the 
exclusion of artistic material conveyed by the companies mentioned. The research questions whether the judicial protection in the specific case is compatible with the parameters defined by the inter-American Human Rights System in relation to the lawful restriction of freedom of expression, which are binding for the Brazilian State. The investigation was carried out using the deductive method and from documentary and bibliographic sources, with emphasis on decisions and reports by the Inter-American Court and Commission. The development of the work is divided into two parts: first, the factual and legal aspects of the concrete conflict were analyzed, and then the parameters that define freedom of expression in the inter-American System were investigated. It was concluded that the judicial decision of the local judicial body contradicted the regional determinations regarding the protection of human rights.

KEYWORDS: Fundamental rights. Freedom of expression. Censorship. Brazilian Supreme Court. Inter-American human rights system.

\section{Introdução}

Os textos constitucionais brasileiros, desde 1824 até 1988, sempre prezaram pela positivação da liberdade de expressão - e manifestação do pensamento - enquanto direito fundamental $^{92}$. A constante repetição dessa cláusula, embora com diferenças em alguns nuances decorrentes da maior ou menor abertura democrática de cada experiência constitucional (monárquica, republicana ou ditatorial), autoriza o observador a dizer que o Estado, pelo menos do ponto de vista formal-regulamentar, tradicionalmente assegura aos seus cidadãos a prerrogativa de manifestarem-se livremente, seja no campo das ideias, da imprensa, das artes, da ciência e afins.

Essa característica do Estado brasileiro, contudo, vem sofrendo tensões nos últimos tempos. Notavelmente a partir da vitória eleitoral do atual Presidente da República, Jair Messias Bolsonaro (sem partido), em 2018, grupos religiosos que manifestam intolerância para com obras que satirizam seus dogmas de fé vêm buscando meios, inclusive institucionais, de bloquear a divulgação das mensagens por si hostilizadas ${ }^{93}$. Foi isso o que ocorreu em 07/01/2020, quando o Desembargador Benedicto Abicair, da Sexta Câmara Cível

\footnotetext{
${ }^{92}$ Numa rápida análise, cf. o art. 179, IV, da Constituição Política do Império do Brazil, de 1824; o art. 72, § 12, da Constituição da República dos Estados Unidos do Brasil, de 1891; o art. 113, 9으, da Constituição da República dos Estados Unidos do Brasil, de 1934; o art. 122, 15, da Constituição dos Estados Unidos do Brasil, de 1937; o art. 141, § 5o, da Constituição dos Estados Unidos do Brasil, de 1946; o art. 150, § 8ㅇ, da Constituição da República Federativa do Brasil, de 1967; o art. 153, § 8ㅇ, da Emenda Constitucional n. 01, de 1969; e o art. 5o, IV e IX, da Constituição da República Federativa do Brasil, de 1988.

${ }^{93}$ Com isso não se está aqui pressupondo que, apenas a partir de 2019, medidas legislativas e jurisdicionais vêm sendo tentadas no sentido de bloquear a divulgação de conteúdos humorísticos que satirizam elementos religiosos. O fato, no entanto, é que, a partir de tal ano, demandas dessa natureza passaram a ecoar mais na esfera pública e encontrar recepção positiva, p. ex., no Poder Judiciário, o que será objeto de análise nesse texto.
} 
do Tribunal de Justiça do Rio de Janeiro (TJRJ), determinou a suspensão do episódio especial de natal intitulado "A Primeira Tentação de Cristo", produzido pelo grupo humorístico Porta dos Fundos e divulgado no serviço de streaming ${ }^{94}$ Netflix. Posteriormente, tal decisão foi suspensa por ordem do Presidente do Supremo Tribunal Federal (STF), Ministro Dias Toffoli, em 09/01/2020.

Um dos elementos que mais chama a atenção no julgamento monocrático proferido no âmbito estadual é o constante recurso, por parte do relator, às normas internacionais de direitos humanos e à jurisprudência dos seus órgãos de monitoramento, em especial as Cortes Europeia e Interamericana de Direitos Humanos. Ao caso, a atenção que se pode atribuir à palavra do ente europeu é modesta em razão da não vinculação do Estado brasileiro às regras produzidas no âmbito do Conselho da Europa ${ }^{95}$; no entanto, a situação não é a mesma com relação à contraparte americana, uma vez que o Brasil é signatário ${ }^{96}$ da Convenção Americana sobre Direitos Humanos (1969) e a Corte Interamericana é sua intérprete oficial e mais importante ${ }^{97}$, além de o Estado brasileiro ter voluntariamente se submetido à sua jurisdição ${ }^{98}$.

O que se buscará compreender neste trabalho é se a alusão feita pelo relator estadual às normas e decisões do sistema interamericano de direitos humanos é compatível, ou não, com o raciocínio por si apresentado em sua decisão monocrática, em especial quando o que está em análise é a proteção de um direito humano (previsto em tratado) e fundamental (tutelado na Constituição Federal de 1988) obstaculizado no ambiente digital (plataforma de streaming). Mais especificamente, problematiza-se: a restrição à liberdade de expressão artística verificada no caso Porta dos Fundos e Netflix atinente ao especial de natal de 2019 se coaduna com os parâmetros definidos no âmbito interamericano para a restrição lícita desse direito?

A realização da pesquisa seguiu o método dedutivo e teve como base a análise dos principais documentos normativos que permeiam o debate, tais como: a Constituição Federal

\footnotetext{
94 Já bastante popularizadas no Brasil, as plataformas de streaming consistem em mecanismos digitais, acessíveis por meio da internet, pelas quais os usuários acessam pacotes de dados por meio de distribuição digital sem que haja descarga destes dados, ou seja, tornando desnecessária a ocupação de espaço no disco rígido dos equipamentos eletrônicos dos consumidores. Estes serviços já atingiram uma variedade de tipos de conteúdo: música, filmes, jogos digitais, livros etc. A Netflix trata-se de uma das maiores corporações do mundo no segmento de streaming de filmes, documentários e séries.

${ }^{95}$ Para uma análise da aplicabilidade da liberdade de expressão no âmbito da internet pela Corte Europeia de Direitos Humanos, cf. HERTIG RANDALL, 2016.

${ }^{96}$ Promulgação interna ocorrida por meio do Decreto n. 678, de 06 de novembro de 1992.

${ }^{97}$ Pode-se extrair tal raciocínio a partir da leitura conjugada dos arts. 66 a 69 do texto convencional.

${ }^{98}$ Cf. art. 1 o do Decreto n. 4.463, de 08 de novembro de 2002.
} 
de 1988, a Convenção Americana sobre Direitos Humanos (1969) e as decisões tomadas nos âmbitos doméstico (decisões monocráticas do Desembargador relator do TJRJ e do Ministro Dias Toffoli, do Supremo Tribunal Federal) e internacional (jurisprudência da Corte Interamericana de Direitos Humanos). Buscou-se também amparo nos materiais produzidos pela Relatoria Especial para a Liberdade de Expressão da Comissão Interamericana de Direitos Humanos, que já deu especial atenção, em duas oportunidades, à proteção desse direito no âmbito da internet. $\mathrm{O}$ material documental citado foi cotejado à luz da literatura que enfrenta o assunto nos aspectos constitucional e internacional (monografias, capítulos de livros e artigos de periódicos).

O desenvolvimento do artigo se dividirá em dois momentos. Num primeiro instante, será apresentado o delineamento do processo judicial envolvendo o Porta dos Fundos e a Netflix a fim de extrair dos votos do Desembargador relator no TJRJ e do Ministro Presidente do STF quais as razões jurídicas que os levaram a tomar posicionamentos divergentes $^{99}$. Se buscará dar destaque, nesse ponto, aos instantes em que tais decisões recorrem à autoridade normativa e argumentativa do sistema interamericano de direitos humanos, seja citando a Convenção Americana sobre Direitos Humanos (1969) ou a jurisprudência regional. Aqui também serão comentadas as principais normas existentes na jurisdição doméstica que tratam do tema da liberdade de expressão, em especial na internet, a fim de testar os limites jurídicos da argumentação apresentada na decisão ora suspensa.

A seção posterior terá como foco os parâmetros definidos pelo sistema interamericano de direitos humanos no que diz respeito à possibilidade de restrição da liberdade de expressão pelo Estado, com ênfase no ambiente digital. Serão analisados os principais casos julgados pela Corte Interamericana de Direitos Humanos sobre a matéria, tanto em seu exercício consultivo quanto na jurisdição contenciosa, e, após isso, o material produzido pela Relatoria Especial para a Liberdade de Expressão da Comissão Interamericana de Direitos Humanos, que já elaborou documentos especificando como tratar esse tema no espaço virtual. Investigar isso proporcionará o confronto entre o que restou decidido na segunda instância fluminense com as obrigações internacionais assumidas pelo Estado brasileiro no âmbito regional.

As restrições aos direitos humanos e fundamentais realizadas pelo Estado devem ser mínimas e, se for o caso de ocorrerem, estritamente justificadas. Os ônus impostos para tal

\footnotetext{
99 Deve-se levar em consideração que este texto foi escrito nos meses de janeiro e fevereiro de 2020. Alterações posteriores no andamento do processo judicial devem ser desconsideradas, uma vez que o pesquisador não pode se antecipar ao comportamento processual das partes ou dos juízes.
} 
justificação, num mundo conectado por tratados, não são apenas de índole interna; os direitos humanos internacionais impõem responsabilidades aos agentes públicos, que não podem tomar decisões ao arrepio daquilo que o próprio Estado assumiu. É isso que se buscará verificar a seguir.

\section{A liberdade de expressão do pensamento enquanto direito fundamental (inclusive na internet) e a análise do conflito jurisdicional do Porta dos Fundos e da Netflix}

O ordenamento jurídico brasileiro, que possui na Constituição Federal de 1988 o seu ápice normativo, protege textualmente a liberdade de expressão do pensamento em vários dispositivos. Descendo à legislação infraconstitucional, sua guarida se dá também no ambiente digital, algo propiciado a partir da vontade do Estado, manifestada pelos Poderes Executivo e Legislativo, de estabelecer os parâmetros definidores que marcam a tutela da internet no Brasil. Como o caso ora analisado diz respeito ao tolhimento da liberdade de expressão ocorrido em plataforma de streaming, faz-se necessário olhar para ambos os níveis normativos.

Quando trata dos direitos e garantias fundamentais, logo no início de seu texto, a Constituição expõe que é livre a manifestação do pensamento, sendo vedado o anonimato, e que a expressão da atividade intelectual, artística, científica e de comunicação goza de igual tratamento, independentemente de censura ou licença do poder público (art. $5^{\circ}$, IV e IX); mais além, no capítulo pertinente à comunicação social, a Constituição determina que a manifestação do pensamento, a criação, a expressão e a informação, sob qualquer forma, processo ou veículo não poderão sofrer restrição, observado o próprio texto constitucional, além de ser vedada toda e qualquer censura de natureza política, ideológica e artística (art. 220 , caput e $\left.\S 2^{\circ}\right)$.

O legislador tratou da liberdade de expressão enquanto norma infraconstitucional com direcionamento específico para o ambiente digital. A Lei n. 12.965, de 23 de abril de 2014, conhecida como o "Marco Civil da Internet"100, estabeleceu como um dos seus eixos principiológicos a liberdade de expressão. A legislação determina, p. ex., que tem como

\footnotetext{
${ }^{100}$ A Lei n. 12.965/2014, criada no contexto das revelações de espionagem praticadas pelo governo norteamericano denunciadas por Edward Snowden, possui uma textualidade aberta e principiológica. Esta característica acentua o papel do Poder Judiciário na sua interpretação e uniformização (SOUZA; LEMOS; BOTTINO, 2017).
} 
fundamento a liberdade de expressão (art. $2^{\circ}$ ) e que a disciplina do uso da internet no Brasil tem como um dos princípios a garantia da liberdade de expressão, de comunicação e de manifestação do pensamento, nos termos da Constituição Federal de 1988 (art. $3^{\circ}$, I).

Quando se analisa a legislação em abstrato, verifica-se a propensão do Estado brasileiro em proteger a liberdade de expressão e o direito de todos de manifestar o seu pensamento, sem censura ou licença prévias, vedando-se apenas o anonimato (MACHADO, 2013). É a própria Constituição que estabelece a proibição de criar-se no país órgão censor responsável pela averiguação prévia de conteúdos que possam ser veiculados nos mais diversos ambientes, sejam físicos, televisivos ou virtuais. Eventuais irritações oriundas do exercício dessa liberdade devem ser resolvidas no campo da responsabilidade civil, mas não com tolhimento do exercício de um direito fundamental, como a própria legislação deixa claro. Com o advento das tecnologias da informação e comunicação nos últimos anos, que proporcionam a elaboração e divulgação de mídias de uma forma muito mais facilitada e democratizada $^{101}$, o asseguramento de tal direito torna-se mais importante frente às possibilidades de insatisfações geradas a partir do choque de ideias havidos na esfera pública.

É consenso na literatura especializada que a proteção à liberdade de expressão é um aspecto essencial da democracia. Como sugere Hertig Randall (2016), o asseguramento de tal direito é condição basilar para a evolução de uma sociedade democrática, uma vez que a proteção direcionada à mídia, às instituições da sociedade civil e às pessoas em geral tornamnas aptas a exercer o papel de vigilantes daqueles que estão no poder para capacitar os indivíduos ao exercício da cidadania e a moldar a opinião pública em matérias de relevante interesse social. Com égide na premissa de que a democracia não é apenas a regra da maioria e requer o pluralismo e a tolerância, a autora destaca que proteger as opiniões dissonantes e minoritárias é um pré-requisito para o avanço do conhecimento e do progresso.

\footnotetext{
101 Oliva e Antonialli (2019, pp. 20-21) concordam com esta perspectiva ao comentarem sobre a proliferação cada vez maior de conteúdos humorísticos, os quais são capazes de gerar cizânias jurídicas, advinda da revolução digital e da efervescência dos aplicativos: "O direito à livre manifestação do pensamento pode se fazer sentir de várias formas. A liberdade para se fazer humor é certamente uma delas. Isso porque a via humorística, muitas vezes, tem o poder de chamar a atenção das pessoas para temas sensíveis ou controversos, abrindo caminho para a crítica e participação política. Embora a utilização do humor como forma de questionamento não seja algo novo na sociedade, parece razoável dizer que a Internet abriu novos canais e agregou atores ao processo de criação de conteúdos de humor, seja porque facilitou a sua publicação, que acontece em uma gama bem mais variada de plataformas, seja porque tornou menos custoso o seu processo de produção. Se antes era necessário investir em equipamentos ou em cursos de habilidades específicas, como edição e tratamento de fotos, hoje a maioria dos dispositivos já oferecem recursos para gravação e edição de conteúdos gratuitamente. Ferramentas específicas também surgiram para auxiliar esses processos, como os geradores automáticos dos chamados 'memes' (imagens acompanhadas de texto humorístico)."
} 
No Brasil, também não faltam autores que se alinham com essa percepção do valor jurídico da liberdade de expressão associado ao campo democrático e pluralista. Aguiar (2013) elenca três vertentes pelas quais é importante proteger a liberdade de expressão: a individual, a social e a democrática. No primeiro aspecto, garantir às pessoas que possam manifestar seu pensamento garante-lhes autonomia responsável por potencializar o desenvolvimento da sua personalidade; no âmbito social, a garantia da liberdade de expressão serve como mecanismo de busca da verdade, uma vez que ela não é única/absoluta e todos devem se esforçar para construí-la por meio dos diferentes discursos que ecoam socialmente, cabendo sempre refutação e acolhimento; por último, a liberdade de expressão assegura uma democracia para além da forma representativa no instante em que proporciona uma materialidade participativa por meio da qual todos podem se manifestar na esfera pública, algo potencializado com o advento das tecnologias da informação e comunicação.

A partir do momento em que o Estado se estruturou como protetor da liberdade de expressão nas suas mais diversas variáveis (liberdades de opinião, de credo, artística, informacional etc.), assim como assumiu obrigações no cenário internacional a esse respeito $^{102}$, cabe a ele envidar esforços no sentido de evitar que atos seus ou de particulares impeçam a manifestação do pensamento de alguém, respeitados os parâmetros constitucionais $\left(\right.$ SOARES, 2019) ${ }^{103}$. Verificada alguma violação à liberdade de expressão, cabe ao Estadojuiz reconstituir a situação à normalidade constitucional. O problema é que, algumas vezes,

\footnotetext{
${ }^{102}$ Este assunto será mais detalhado na próxima seção.

103 Estas premissas se coadunam com o pensamento de Aguiar (2013, pp. 241): “De acordo com a opção política que é feita na constituição e na condução do Estado, este poderá se portar como um ator que observa as múltiplas expressões de manifestações que se exteriorizam livremente no convívio diário entre os membros da sociedade, interferindo apenas a partir do momento em que sejam ultrapassados os limites estabelecidos pelos valores acolhidos e determinados pelas pessoas, que geralmente implica na ofensa à liberdade de outros. Aqui a sociedade se auto determina e o Estado é mínimo, no que se refere à ingerência na liberdade de expressão. Este modelo atribui às próprias pessoas a responsabilidade direta por seus atos, isto é, dá-lhes direitos e liberdades, mas também deveres e obrigações, situando-se a responsabilidade como elo entre as diversas expressões, de forma que, numa situação ideal, todos podem igualmente se manifestar, mas devem procurar não violar a dignidade do outro, nem os seus direitos, entendendo claramente que nenhum deles pode ser tomado como absoluto. Da mesma forma, um crente pode não aceitar o ateísmo ou uma expressão religiosa (sagrada) que não seja a sua, mas deve, por mínimo, respeitar o igual direito de manifestação de outras crenças, uma vez que todos são portadores da mesma dignidade humana e merecem expressá-la livremente por meio do desenvolvimento de suas potencialidades físicas, psicológicas, culturais e espirituais. Se para as principais religiões monoteístas, o homossexualismo, por exemplo, é um 'pecado', a realidade dos direitos humanos que amplia a concepção de liberdade, entende que esta expressão da diversidade e individualidade humana pode se manifestar livremente. Isto não implica na necessidade de mudança de crença para perceber a riqueza de manifestações da personalidade humana, mas requer, contemporaneamente, uma atenção especial da sociedade e do Estado aos perigos da manipulação de opinião por meio da concentração midiática que muitas vezes exacerba as diferenças, transformando-as em trampolim para a intolerância e a discriminação."
} 
são membros do Poder Judiciário quem protagonizam o tolhimento indevido a essa liberdade fundamental, como se deu no caso Porta dos Fundos e Netflix.

O fato é que, em 03/12/2019, o canal Porta dos Fundos e a rede de streaming Netflix lançaram, na plataforma desta última, o Especial de Natal "A Primeira Tentação de Cristo”. Na obra audiovisual, personagens tradicionais da Bíblia (Deus, Jesus, Maria, José etc.) foram retratados com posturas que não são encontradas no cânone bíblico a fim de ensejar a transmissão do humor que marca as produções do canal. Destaca-se neste aspecto a retratação de Jesus Cristo como gay, que teria um caso amoroso com Lúcifer, e o triângulo amoroso de cunho sexual vivido entre Deus, Maria (que, na obra, não é virgem) e José.

Várias associações religiosas manifestaram insatisfação com tal representação e acionaram o Poder Judiciário a fim de coibir a veiculação da obra audiovisual. A maioria das tentativas restou infrutífera. Contudo, destaca-se neste ponto a Ação Civil Pública n. 0332259-06.2019.8.19.0001, em trâmite na 16ª Vara Cível da Comarca do Rio de Janeiro/RJ, ajuizada pela Associação Centro Dom Bosco de Fé e Cultura contra o Porta dos Fundos Produtora e Distribuidora Audiovisual S/A e a Netflix Entretenimentos Brasil LTDA., porque foi por meio do recurso de Agravo de Instrumento decorrente deste feito que a obra artística restou suspensa, ainda que por pouco tempo.

Após ter o pedido liminar em primeiro grau indeferido pela juíza Adriana Sucena Monteiro Jara Moura, em decisão de 19/12/2019, a associação protocolou o Agravo de Instrumento com Pedido de Efeito Suspensivo n. 0083896-72.2019.8.19.0000, distribuído para a Sexta Câmara Cível do TJRJ, sob a relatoria do Desembargador Benedicto Abicair. Este último, em 07/01/2020, monocraticamente, atribuiu efeito suspensivo à decisão interlocutória da juíza Adriana Moura a fim de determinar às partes agravadas que indisponibilizassem na rede de streaming o episódio especial de natal. Saliente-se que o relator do recurso tolheu a liberdade de expressão (na modalidade artística) do canal Porta dos Fundos reconhecendo que sequer analisou o conteúdo audiovisual de forma minuciosa ${ }^{104}$.

\footnotetext{
${ }^{104}$ O reconhecimento da maneira apressada pela qual tomou contato com a obra consta no próprio voto do Desembargador: "A bem da verdade, nessa fase preliminar não cabe maiores erudições para embasar qualquer decisão, diante da exiguidade do tempo para se decidir com quem está a razão, mas, sim, qual dano de maior potencialidade precisa ser evitado, até porque sequer é possível uma avaliação mais detida do 'Especial de Natal Porta dos Fundos: A Primeira Tentação de Cristo', pois, até aqui, somente tinha conhecimento dessa produção através de notícias na mídia eletrônica, que acompanho, e as que me chegam diariamente, sem me ater à leitura daquilo que não me interessa, desconhecendo, inclusive, o trabalho e conceito dos artistas mencionados. Mas, após ler o material disponibilizado no feito, até então, bem como assistir, rapidamente, o episódio, pude constatar tratar-se de uma aparente 'sátira' de personagens do cristianismo, extraídos da Bíblia, a obra mais lida no mundo."
} 
Em várias passagens da sua fundamentação, conquanto alegue não ser um crítico de arte, o relator qualifica a associação recorrente como uma entidade que busca preservar os valores morais e cristãos da sociedade brasileira e os recorridos enquanto entidades empresariais que visam apenas a lucratividade; além disso, consta na decisão que a liberdade de expressão não pode admitir discursos que não deixem claro tratar-se de "crítica", "debate" ou "achincalhe". Ou seja, o Desembargador arvorou-se na condição de censor do nível de acidez que se pode apresentar no debate da esfera pública. Também não faltaram críticas à suposta falta de "centralidade" e "comedimento" do canal Porta dos Fundos ao se manifestar sobre sua obra nas redes sociais, algo visto com desprezo no voto ${ }^{105}$. Importa mencionar também que, em determinada passagem, o relator fala na jurisprudência de uma suposta “Corte Internacional de Direitos Humanos", a qual, pelo contexto discursivo, aparentemente trata-se da Corte Interamericana de Direitos Humanos.

O dispositivo decisório justifica o deferimento do pleito suspensivo do agravo a partir do fundamento de que, dado o fato de a sociedade brasileira ser "majoritariamente cristã", é necessária a suspensão da veiculação da obra "para acalmar os ânimos"106. O dever constitucional de fundamentação das decisões judiciais de maneira técnico-jurídica foi

105 Cf. trecho do voto: "Vejo com bons olhos todo e qualquer debate ou crítica à religião, racismo, homossexualidade, educação, saúde, segurança pública e liberdade de imprensa, artística e de expressão, desde que preservados a boa educação, o bom senso, a razoabilidade e o respeito à voz do outro. Caso contrário passa-se à agressão verbal, muitas vezes com desdobramentos físicos. [...] De um lado tem-se a Agravante que busca defender direitos da comunidade cristã, a mais expressiva no Brasil, que se sente aviltada por uma 'produção artística'. Do outro lado têm-se empresas, com fins lucrativos, uma que se apossou de uma obra de domínio público, milenar, que congrega milhões de fiéis seguidores, fanáticos ou não, que cultuam a religião e Santos, em questão, outra que exibe a 'obra' [...] As liberdades de expressão, artística e de imprensa são primordiais e essenciais na democracia. Entretanto, não podem elas servir de desculpa ou respaldo para toda e qualquer manifestação, quando há dúvidas sobre se tratar de crítica, debate ou achincalhe. O debate consiste na troca de opiniões. A crítica na avaliação contrária a gostos ou princípios. Achincalhe consiste em desmerecer algo ou alguém por motivos subjetivos, sem medir consequências. Assim que interpreto. $\mathrm{O}$ que se pretende, nos autos, é apurar, dentro dos princípios morais, constitucionais e legais como caracterizar o procedimento da primeira Agravada com sua 'obra de arte'. Ainda não há subsídios suficientes, sob minha ótica, para essa interpretação definitiva. [...] Destaco, ainda, que a primeira Agravada não foi centrada e comedida ao se manifestar, nas redes sociais, conforme transcrito nas razões da ora Agravante, pois, ao meu ver, poderiam justificar sua 'obra' através de dados técnicos e não agindo com agressividade e deboche. Maior comedimento possibilitaria, talvez, debate em nível mais elevado, sem ferir, acintosamente, suscetibilidades. [...] Daí a minha avaliação, nesse momento, é de que as consequências da divulgação e exibição da 'produção artística' da primeira Agravada são mais passíveis de provocar danos mais graves e irreparáveis do que sua suspenção [SIC], até porque o Natal de 2019 já foi comemorado por todos."

${ }^{106}$ Nas palavras do relator: "Por todo o exposto, se me aparenta, portanto, mais adequado e benéfico, não só para a comunidade cristã, mas para a sociedade brasileira, majoritariamente cristã, até que se julgue o mérito do Agravo, recorrer-se à cautela, para acalmar ânimos, pelo que CONCEDO A LIMINAR [SIC] na forma requerida." 
traduzido pela expressão transcrita, algo que foi levado em consideração pelas partes prejudicadas com a decisão quando do momento da interposição do recurso cabível ${ }^{107}$.

Os recorridos buscaram reverter tal decisão perante o Supremo Tribunal Federal, que, além de se constituir no órgão máximo da jurisdição constitucional brasileira, tradicionalmente possui uma jurisprudência que prioriza o resguardo da liberdade de expressão em suas mais variadas modalidades ${ }^{108}$. Com o protocolo da Reclamação 38.782/RJ, distribuída ao Min. Gilmar Mendes, o Min. Dias Toffoli lavrou decisão monocrática, em regime de plantão judiciário, cassando a decisão do Desembargador fluminense e oportunizou aos reclamantes a veiculação do conteúdo audiovisual do especial de natal. Para o Presidente do STF, a leitura constitucional da liberdade de expressão protege até mesmo conteúdo ácido e capaz de chocar a sociedade.

Em seu voto, o Min. Dias Toffoli fez um apanhado da ampla jurisprudência da Corte no sentido de priorizar a proteção da liberdade de expressão em seus distintos nuances ${ }^{109}$. Há menção especial ao julgamento da Arguição de Descumprimento de Preceito

${ }^{107}$ A fundamentação do relator foi hostilizada e atraiu a crítica dos meios jornalísticos geral e especializado na cobertura de temas jurídicos, os quais buscaram as opiniões de juristas para comentar o caso. A título de exemplo, cf. FOLHA DE SÃO PAULO, 2020; e CONSULTOR JURÍDICO, 2020.

${ }^{108}$ Soares (2019, pp. 78), ao elencar várias decisões em que o STF atuou no sentido de proteger a liberdade de manifestação artística (Ação Direta de Inconstitucionalidade (ADI) 4.451/DF, ADI 4.815/DF, Suspensão de Liminar 1.248/RJ e Reclamação 36.742/RJ), categoricamente afirma: "A tendência na jurisprudência do STF é considerar inconstitucionais as leis que proíbem, em tese, a expressão artística e indicar a responsabilização ulterior, em casos de violação. Há decisões recentes e emblemáticas do STF nesse sentido."

${ }^{109}$ Foram principalmente duas as razões da suspensão da decisão local: a concretização da liberdade de expressão enquanto corolário da dignidade humana (i) e a voluntariedade a que estão sujeitas as pessoas que querem ver o especial de natal (ii). Sobre tais pontos, confira-se trechos do voto do Presidente: "Ao decidir a SL no 1.248/RJ-MC e, mais recentemente, a STP no 165/RJ, consignei a liberdade de expressão, condição inerente à racionalidade humana, como direito fundamental do indivíduo e corolário do regime democrático, destacando que [...]. Acerca do tema da liberdade de expressão, esta Corte, no julgamento da ADPF no 130 , debruçou-se com percuciência sobre a temática, ressaltando, na ocasião, a plenitude do exercício da liberdade de expressão como decorrência imanente da dignidade da pessoa humana e como meio de reafirmação/potencialização de outras liberdades constitucionais. Nessa linha de entendimento, o Plenário do STF, ao julgar a ADI no 4.451/DF, ressaltou que '[o] direito fundamental à liberdade de expressão não se direciona somente a proteger as opiniões supostamente verdadeiras, admiráveis ou convencionais, mas também aquelas que são duvidosas, exageradas, condenáveis, satíricas, humorísticas, bem como as não compartilhadas pelas maiorias' (Rel. Min. Alexandre de Moraes, DJe de 6/3/2019). [...] Ademais, quando demandado a se manifestar sobre o conteúdo da liberdade de crença (CF/88, art. 5o, VI e VIII) e da laicidade do Estado (CF/88, art. 19, I) na ADI no 4.439/DF, foram duas as premissas consideradas igualmente relevantes para fins de se observar os preceitos, quais sejam: i) a 'voluntariedade' da exposição ao conteúdo e ii) a vedação de que 'o Poder Público crie de modo artificial seu próprio ensino religioso' ou que favoreça ou hierarquize 'interpretações bíblicas e religiosas de um ou mais grupos em detrimento dos demais'. Nesse ponto, impende destacar a primeira parte da decisão proferida pelo Desembargador Cezar Augusto Rodrigues Costa no Al no 0343734-56.2019.8.19.0001, fazendo referência à decisão de primeira instância que indeferiu o pedido liminar formulado na ACP no 0332259- 06.2019.8.19.0001: '[...] a circulação do trabalho de humor e sátira se dá apenas através do streaming e em locais cujo acesso é voluntário e controlado, de modo que o poder de censura fica nas mãos de cada pessoa isoladamente. Assim, a preocupação com a manutenção dos valores que [a Associação Centro Dom Bosco de Fé e Cultura] entende caros podem ser protegidos pelos que detêm o 
Fundamental (ADPF) 130/DF, quando, ao se aferir à incompatibilidade da Lei n. 5.250, de 09 de fevereiro de 1967 (Lei de Imprensa), com a Constituição Federal de 1988, consignou o STF que a proteção da liberdade de expressão requer até mesmo a imposição de um estado de momentânea paralisia da inviolabilidade de certos direitos fundamentais, como a intimidade, a vida privada, a imagem e a honra de terceiros (MACHADO, 2013). Possíveis limitações e restrições à liberdade de expressão só encontram guarida no próprio texto constitucional, não podendo o legislador ordinário ou as autoridades judiciais criar figuras inéditas com o intuito de regulá-la.

Apesar de o Supremo Tribunal Federal ter cassado a decisão do órgão fluminense, o caso concreto não deixa de lançar preocupações sobre o modo como a liberdade de expressão é tratada no Judiciário brasileiro. Pesquisa de Oliva, Antonialli e Dos Santos (2019) deixa claro que, na jurisdição ordinária doméstica, a maioria dos conflitos envolvendo a contraposição entre a liberdade de expressão e a proteção da honra/imagem se resolve em favor do binômio. Isso mostra como, a despeito da jurisprudência consolidada do STF, juízes e desembargadores, nas instâncias mais próximas dos jurisdicionados, protagonizam uma leitura da Constituição desalinhada com o respeito lhe empregado pelo órgão de cúpula ${ }^{110}$.

Este é um tema que não importa apenas à tutela constitucional. Positivada em tratados de direitos humanos ratificados pelo Brasil, a liberdade de expressão também encontra guarida em órgãos protetivos internacionais aos quais a jurisdição brasileira se submete. A próxima seção analisará especificamente quais os parâmetros definidos pelo sistema interamericano de direitos humanos para a restrição lícita desse direito e se isso foi respeitado na decisão estadual.

poder familiar, o poder de tutela e curatela, enfim, por todos aqueles que estão de algum modo na posição de garantidor e mantenedor destes valores. Quanto aos demais, aos maiores, capazes, caber-lhes-á a reflexão crítica, ou o repúdio e o desprezo, dentre as múltiplas possibilidades'."

${ }^{110}$ São preocupantes os efeitos colaterais nocivos sobre os produtores de conteúdo das decisões tomadas na jurisdição ordinária acerca da liberdade de expressão, os quais se veem cada vez mais desencorajados a continuar exercendo e divulgando sua criatividade, em especial no campo do humor: "Assim, notamos que os produtores de conteúdo entrevistados tomam decisões com base em uma percepção de que se tornar réu em um processo judicial significa, quase que automaticamente, ser condenado ao final. Essa percepção se deve, muito provavelmente, à tutela mais substantiva dos direitos da personalidade (sobretudo honra e imagem) pelo Judiciário, em detrimento da liberdade de expressão: se os tribunais não são vistos como defensores da liberdade de expressão, é de se esperar que os produtores de conteúdo, diante de alguma ameaça de processo, sejam intimidados." (OLIVA; ANTONIALLI; DOS SANTOS, 2019, pp. 39-40). 


\section{Parâmetros de limitação da liberdade de expressão na internet definidos pelo Sistema Interamericano de Proteção dos Direitos Humanos}

A partir do fim da Segunda Guerra Mundial (1939-1945), com o estabelecimento das principais estruturas normativas, judiciais e quase-judiciais de promoção dos direitos humanos, diversos documentos (especialmente declarações e tratados) passaram a fixar, no âmbito internacional, deveres estatais (assumidos voluntariamente) de assegurar aos indivíduos, sejam estes seus nacionais ou não, uma série de prerrogativas. Em vários momentos, tais direitos humanos reproduzem a essência dos direitos fundamentais já inscritos nas constituições domésticas, com o diferencial de que, na esfera internacional, os órgãos de monitoramento são as entidades responsáveis por dar a última palavra em matéria de interpretação sobre o alcance e as obrigações decorrentes destes documentos.

$\mathrm{O}$ direito à liberdade de expressão, tradicionalmente previsto em diversas constituições do hemisfério ocidental, está previsto nos principais documentos que veiculam direitos humanos internacionais. No âmbito da Organização das Nações Unidas (ONU), chamado na literatura de sistema universal de proteção dos direitos humanos, pode-se citar, a título de exemplo, as proteções conferidas pela Declaração Universal dos Direitos Humanos $(1948)^{111-112}$, que garante a todos os seres humanos a liberdade de expressão e opinião, além da liberdade de, sem interferência de terceiros, ter opiniões, procurar, receber e transmitir informações e ideias por quaisquer meios independentemente de fronteiras (art. XIX); e pelo Pacto Internacional dos Direitos Civis e Políticos (1966) ${ }^{113}$, que veda a possibilidade de alguém ser molestado por suas opiniões (art. 19(1)); garante a todos a prerrogativa de, por qualquer meio e independentemente de fronteiras, exercer sua liberdade de expressão (art. 19(2)); e determina que eventual restrição a esses direitos deve ser legalmente prevista apenas com os objetivos de assegurar o respeito aos direitos e à reputação de terceiros ou proteger a segurança nacional, a ordem, a saúde ou a moral públicas (art. 19(3)).

Assim como se deu na geografia europeia, os Estados do continente americano também formularam um sistema protetivo regional de direitos humanos. Com a criação da Organização dos Estados Americanos (OEA), foram elaborados tratados, declarações e órgãos

\footnotetext{
${ }^{111}$ Adotada e proclamada pela Resolução n. 217 (III) da Assembleia Geral da ONU, em 10 de dezembro de 1948.

112 Pelo fato de aprofundar a expressão "direitos humanos" prevista na Carta de São Francisco (1945), a Declaração Universal dos Direitos Humanos (1948) é considerada a sua "intepretação autêntica" (MUÑOZ, 2018).

${ }^{113}$ Internalizado na ordem jurídica brasileira por meio do Decreto n. 592, de 06 de julho de 1992.
} 
específicos de monitoramento da aplicabilidade de tais documentos, tendo como principais instrumentos neste último aspecto a Comissão e a Corte Interamericanas de Direitos Humanos ${ }^{114}$. Os documentos criados no sistema regional preveem várias modalidades de direitos humanos, a exemplo das liberdades de expressão e de manifestação do pensamento.

A Declaração Americana dos Direitos e Deveres do Homem (1948) ${ }^{115}$, em seu capítulo primeiro, garante a todos os direitos à liberdade de investigação, de opinião e de expressão do pensamento, por qualquer meio (art. IV); já a Convenção Americana sobre Direitos Humanos (1969), que instituiu um regime complementar continental de custódia das liberdades fundamentais a ser ativado apenas quando as ordens jurídicas domésticas não lograrem êxito em fazê-lo espontaneamente ${ }^{116}$, expõe que os direitos à liberdade de pensamento e de expressão compreendem a liberdade de buscar, receber e difundir ideias de toda natureza, sem consideração de fronteiras ou meios (art. 13(1)); determina que o exercício desses direitos não pode ser sujeito a censura prévia, mas com possibilidade de responsabilização posterior fixada em lei, desde que para proteger a reputação de outrem ou a

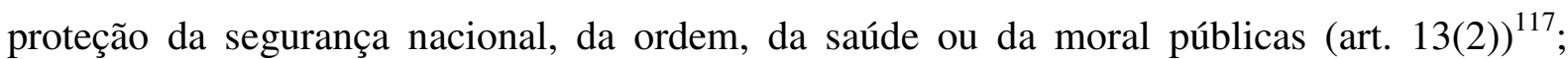
proíbe a restrição à liberdade de expressão por meios indiretos, em especial com abuso de

\footnotetext{
${ }^{114}$ A partir do instante em que os Estados deram esse significativo passo no sentido de fomentar a existência de estruturas político-jurídicas internacionais responsáveis por interpretar a aplicabilidade dos direitos humanos, os quais, muitas vezes, também são direitos fundamentais, ocorreu uma remodelação dos próprios constitucionalismos domésticos, que precisam se adaptar à convivência com tais entes. Para Magalhães (2017, pp. 116), a prática constitucional brasileira precisa se adequar aos tempos da globalização dos direitos humanos fundamentais: "[...] o constitucionalismo brasileiro precisa ser reinterpretado em articulação com o direito internacional, a fim de dar conta das alterações paradigmáticas que ocorreram desde meados do século passado. Com a globalização, as distâncias diminuíram, as comunicações tornaram-se mais rápidas, os avanços tecnológicos constantes, a economia mais dinâmica e os problemas que dela advêm tornaram-se comuns. Problemas comuns não no sentido de triviais, mas de problemas compartilhados pelos Estados. As interações políticas, sociais e jurídicas no mundo globalizado não se encerram mais dentro das estruturas constitucionais dos Estados, tornando possível que questões econômicas, de direitos fundamentais, ou de migrações, surtam efeitos em diferentes partes do globo, ainda que tais Estados permaneçam regidos, no plano político, pela ideia de soberania."

${ }^{115}$ Não deixa de ser curioso notar que a declaração regional foi adotada sete meses antes da Declaração Universal dos Direitos Humanos (1948).

${ }^{116}$ O preâmbulo da Convenção estabelece esse regime de complementaridade/subsidiariedade: "Os Estados americanos signatários da presente Convenção, [...] Reconhecendo que os direitos essenciais do homem não derivam do fato de ser ele nacional de determinado Estado, mas sim do fato de ter como fundamento os atributos da pessoa humana, razão por que justificam uma proteção internacional, de natureza convencional, coadjuvante ou complementar da que oferece o direito interno dos Estados americanos. [...]".

${ }^{117}$ Esta possibilidade de restrição posterior, em caso de abuso do exercício do direito à liberdade de expressão, é referendada na literatura especializada: "Like most fundamental rights, freedom of expression is not absolute. Its exercise can be limited for the sake of protecting conflicting public interests and the rights of others. Accordingly, human rights instruments provide that state measures abridging freedom of expression are justified if they are (1) prescribed by law, (2) pursue a legitimate aim, and (3) are 'necessary in a democratic society', i.e., comply with the principle of proportionality. As the grounds for limitation are broad, they do in practice not significantly limit the states ability to adopt measures interfering with freedom of expression." (HERTIG RANDALL, 2016, pp. 241)
} 
controles sociais ou mesmo dos meios físicos de transmissão de mensagens (art. 13(3)); assegura a possibilidade de o Estado, por meios legais, exercer censura prévia a espetáculos públicos, desde que com o objetivo de regular seu acesso para fins de proteção da moral da infância e da adolescência (art. 13(4)); e determina a obrigação estatal de legislar para proibir propagandas em favor de guerra e apologias ao ódio nacional, racial ou religioso capaz de constituírem incitações à discriminação, à hostilidade, ao crime ou à violência (art. 15(5)).

A Corte Interamericana de Direitos Humanos já possui uma jurisprudência sólida a respeito do alcance do art. 13 da Convenção Americana sobre Direitos Humanos (1969). A primeira vez em que o órgão foi instado a se manifestar sobre o assunto foi em 1985, a pedido do Governo da Costa Rica, quando da emissão do Parecer Consultivo OC 05-85, de 13 de novembro de 1985, tratando sobre a compatibilidade da legislação costarriquenha que tornava obrigatório o registro dos jornalistas em conselho de classe para o exercício da sua profissão à luz dos art. 13 e 29 da Convenção.

Embora a consulta dissesse respeito majoritariamente ao espectro da liberdade de imprensa, uma das modalidades da liberdade de expressão, a argumentação da Corte ofereceu caminhos para se interpretar os dispositivos convencionais para além do que foi estritamente provocado pelo Estado. Dentre as principais compreensões apresentadas pelo órgão, constam as ideias de que, no espectro individual, a liberdade de expressão do pensamento está umbilicalmente relacionada com a garantia de sua difusão, o que torna o tolhimento desta prerrogativa um ataque à própria liberdade de expressão (§ 31); além disso, a liberdade de expressão possui uma dimensão social consistente no direito de as pessoas tomarem conhecimento dos discursos veiculados na esfera pública por outrem, uma vez que os cidadãos têm o direito de conhecer o que os outros pensam a fim de moldar suas próprias convicções (§ 32). Não é possível falar-se em garantia da liberdade de expressão, para a Corte, sem que se garanta simultaneamente os direitos de manifestação e difusão do pensamento com o de terceiros de ter acesso a tais conteúdos (§ 33).

A Corte Interamericana é taxativa ao estabelecer que qualquer tipo de censura prévia, salvo a delineada no art. 13(4), constitui violação ao texto convencional ${ }^{118}$. Não cabe

\footnotetext{
${ }^{118}$ No original: “§ 38. O artigo 13.2 da Convenção define através de que meios podem ser estabelecidas legitimamente restrições à liberdade de expressão. Estipula, em primeiro lugar, a proibição da censura prévia, a qual é sempre incompatível com a plena vigência dos direitos enumerados no artigo 13, salvo as exceções contempladas no inciso 4 referentes a espetáculos públicos, inclusive se se trata, supostamente, de prevenir por esse meio um eventual abuso da liberdade de expressão. Nesta matéria toda medida preventiva significa, inevitavelmente, o prejuízo da liberdade garantida pela Convenção. § 39 . O abuso da liberdade de expressão não pode ser objeto de medidas de controle preventivo, mas fundamento de responsabilidade para quem o tenha cometido. Ainda neste caso, para que tal responsabilidade possa ser estabelecida validamente, segundo
} 
ao Estado restringir o discurso de quem quer que seja ou definir o que pode ser objeto de conhecimento por parte da população. Caso assim atue, estará ele violando sua obrigação convencional. As demais considerações do parecer consultivo versam especificamente sobre a obrigatoriedade do registro profissional de jornalistas, mas esse caso já dá mostras de como a Corte avançaria, no futuro, sobre a matéria.

Nos anos 2000, a Corte voltou a se debruçar sobre o tema da liberdade de expressão, em situação similar à comentada na seção anterior, no julgamento do Caso "A Última Tentação de Cristo" (Olmedo Bustos e Outros) v. Chile (2001). Resumidamente, tratou-se de demanda apresentada à Comissão Interamericana, e posteriormente remetida ao órgão jurisdicional, desencadeada a partir do impedimento imposto pelo Poder Judiciário do Chile acerca da exibição, nos cinemas do país, do filme "A Última Tentação de Cristo" (1988), do cineasta Martin Scorsese. Esta proibição era ancorada em norma constitucional, atualmente revogada, que estabelecia um regime de censura prévia nacional para obras artísticas.

O caso chama a atenção porque o próprio Poder Executivo chileno, responsável pela defesa do Estado perante os órgãos interamericanos, reconhece a inconstitucionalidade e a inconvencionalidade da medida tomada pelo Poder Judiciário doméstico ${ }^{119}$. Sobre o mérito em si do alcance da proteção internacional à liberdade de expressão, a Corte Interamericana reforçou sua dupla concepção individual e social (§§ 64-67). Para o órgão, a primeira modalidade só será efetivamente garantida se a todas as pessoas for assegurada a prerrogativa

a Convenção, é preciso que se reúnam vários requisitos, a saber: a) A existência de fundamentos de responsabilidade previamente estabelecidos, b) A definição expressa e taxativa desses fundamentos pela lei, c) A legitimidade dos fins perseguidos ao estabelecê-los, e d) Que esses fundamentos de responsabilidade sejam 'necessários para assegurar' os mencionados fins. Todos estes requisitos devem ser cumpridos para que se dê cumprimento total ao artigo 13.2."

${ }^{119}$ Esse reconhecimento, contudo, não foi capaz de isentar o Estado da sua responsabilidade no caso: "§ 71. No presente caso, está provado que, no Chile, existe um sistema de censura prévia para a exibição e publicidade da produção cinematográfica e que o Conselho de Qualificação Cinematográfica proibiu, em princípio, a exibição do filme 'A Última Tentação de Cristo' e, depois, ao requalificá-lo, permitiu sua exibição para maiores de 18 anos (par. 60 a, c e d supra). Posteriormente, a Corte de Apelações de Santiago tomou a decisão de deixar sem efeito a decisão do Conselho de Qualificação Cinematográfica em novembro de 1996, devido a um recurso de proteção interposto pelos senhores Sergio García Valdés, Vicente Torres Irarrázabal, Francisco Javier Donoso Barriga, Matías Pérez Cruz, Jorge Reyes Zapata, Cristian Heerwagen Guzmán e Joel González Castillo, 'em nome de [...] Jesus Cristo, da Igreja Católica, e por si mesmos'; decisão que foi confirmada pela Corte Suprema de Justiça do Chile. Este Tribunal considera que a proibição da exibição do filme 'A Última Tentação de Cristo' constituiu, portanto, uma censura prévia imposta em violação ao artigo 13 da Convenção. § 72. Esta Corte entende que a responsabilidade internacional do Estado pode ser gerada por atos ou omissões de qualquer poder ou órgão, independentemente de sua hierarquia, que violem a Convenção Americana. Isto é, todo ato ou omissão, imputável ao Estado, em violação às regras do Direito Internacional dos Direitos Humanos, compromete a responsabilidade internacional do Estado. No presente caso, esta foi gerada em virtude de que o artigo 19, inciso 12 , da Constituição estabelece a censura prévia na produção cinematográfica e, portanto, determina os atos dos Poderes Executivo, Legislativo e Judiciário." 
de, além de produzir seu pensamento e expressão, ter meios adequados para divulga-lo e levalo ao conhecimento do maior número possível de destinatários, seja pelas vias impressa, digital ou qualquer outro meio; no aspecto social, ao se reconhecer que tal liberdade é um meio para intercâmbio de ideias e informações, é direito de qualquer cidadão ter conhecimento da opinião alheia ou das informações veiculadas na esfera pública ${ }^{120}$.

Outra situação analisada pela Corte acerca do mesmo objeto trata-se do Caso Kimel v. Argentina (2008), por meio do qual o órgão analisou a compatibilidade perante o texto convencional da condenação criminal havida em desfavor da vítima pelo Poder Judiciário da Argentina em função das críticas por ele veiculadas em obra que retratou a negligência de servidores públicos quanto à investigação do "Massacre de San Patrício", ocasião em que cinco religiosos foram assassinados por se oporem ao governo ditatorial. A análise da Corte centrou-se especialmente no art. 13 da Convenção Americana sobre Direitos Humanos (1969).

Além de ressaltar mais uma vez o teor individual e social da liberdade de expressão, a Corte enfatizou que, no debate sobre temas de interesse público, não se deve proteger apenas opiniões inofensivas ou bem recebidas pela opinião pública, mas também as que chocam, irritam ou inquietam as pessoas de qualquer setor populacional ( $\$ 88$ ). A liberdade de expressão não dá guarida apenas às mensagens e aos conteúdos tidos como "adequados" pela sociedade, mas também aos que causam incômodo e insatisfação. Mais adiante, a Corte ressaltou que juízos de valor constantes em obras artísticas não podem ser considerados verdadeiros ou falsos, razão pela qual tampouco podem ser objeto de sanção, uma vez que tais qualificativos somente podem ser atribuídos a fatos, não a opiniões ( $§ 93)$.

Por mais que as decisões da Corte Interamericana analisadas não tenham sido proferidas contra o Brasil, elas devem ser levadas em consideração pela jurisdição constitucional porque o Estado não está vinculado apenas ao texto hermético da Convenção Americana sobre Direitos Humanos (1969), da qual ele é signatário, mas também à interpretação lhe atribuída pelo órgão autorizado a dar a palavra final sobre o assunto (MAGALHÃES, 2017). A própria predisposição em ratificar um tratado desta natureza implica na voluntariedade em cumprir, de boa-fé, as determinações do seu principal órgão de

120 As considerações de Aguiar (2013, pp. 243) também se coadunam com o pensamento da Corte Interamericana: “Assim, a liberdade de expressão também pode ser compreendida dentro de uma dimensão de dever positivo do Estado, no sentido de garantir condições jurídicas e materiais necessárias para que todos possam igualmente exercer este direito, coibindo, inclusive, situações que possam não apenas impedir a livre manifestação de opiniões e ideias, mas condicioná-las e manipulá-las, quer pelo próprio Estado, por organizações privadas, ou indivíduos, retirando da pessoa a liberdade garantidora de sua autonomia." 
monitoramento, especialmente pela sua tendência em tornar cada vez mais complexo o conteúdo protetivo da liberdade de expressão (FALSARELLA, 2012) ${ }^{121}$.

A consolidação da jurisprudência interamericana em matéria de liberdade de expressão proporcionou que a Comissão Interamericana de Direitos Humanos, por meio da sua Relatoria Especial para a Liberdade de Expressão, produzisse relatórios sobre o tema tendo como âmbito de aplicação a internet. O primeiro deles, de 2013, elaborado pela relatora especial Catalina Botero Marino, reforça a necessidade do asseguramento de tal direito para a manutenção de uma sociedade democrática (§ 52) e apresenta os condicionantes necessários para a restrição desse direito no meio digital ( $§ 58-67)$ : a determinação deve estar prevista em lei formal e suficientemente clara, sendo insuficientes regulamentos administrativos ou de natureza similar (i); estas restrições devem ser autorizadas pela Convenção Americana e devem ser interpretadas de acordo com uma sociedade democrática e a partir dos parâmetros dos seus órgãos de monitoramento, não podendo o Estado fazer uso de cláusulas abertas (segurança nacional, ordem pública, proteção a direitos de terceiros etc.) para constranger defensores de direitos humanos, jornalistas ou opositores políticos, por exemplo (ii); a medida adotada deve ser pontual e estritamente necessária para atingir o fim perseguido pelo Estado, restando proibidas ações com efeitos genéricos capazes de atingir direitos de outras pessoas (iii); ainda, as providências praticadas para fins de responsabilizar civil e posteriormente o autor do conteúdo objeto de limitação devem obedecer aos parâmetros do devido processo legal e da ampla defesa (iv); por último, mesmo com a natureza intangível do mundo virtual, os Estados com jurisdição sobre estes casos devem ser aqueles com maior proximidade com o seu substrato fático-jurídico, o que pode ser aferido pela nacionalidade do autor e das vítimas, dos locais de suas residências ou outros elementos de conexão (v).

Edison Lanza, outro relator especial sobre a liberdade de expressão, em 2017, produziu mais um documento da mesma natureza. Nesta ocasião, além de reforçar que a

\footnotetext{
${ }^{121}$ Por outro lado, Abbott (2015) alerta para a possibilidade de o nível protetivo atribuído pela Convenção Americana sobre Direitos Humanos (1969) e pela jurisprudência da Corte em matéria de liberdade de expressão ser tensionado pelas obrigações direcionadas aos Estados em decorrência da adesão/ratificação à Convenção Interamericana Contra toda Forma de Discriminação e Intolerância (2013). Isso porque vários dos mandamentos contidos no tratado, em especial os elencados no seu art. 4으, determinam aos Estados-parte que tomem medidas direcionadas a evitar a manifestação de formas de discriminação e intolerância, o que deve ser feito inclusive preventivamente. O autor sustenta que a criação de mecanismos preventivos de inibição destes fenômenos corre o risco acentuado de obstaculizar a manifestação do pensamento livre, dada a possibilidade de isso caracterizar censura à opinião alheia. Ou seja, a liberdade de expressão ficaria à mercê da proteção da honra e da imagem das pessoas não mais a partir do acionamento dos mecanismos reparatórios cíveis de repreensão, mas sim por meio do estabelecimento de órgãos responsáveis por fazer o controle prévio daquilo que se pode, ou não, divulgar/publicar. O autor vê essa possibilidade com preocupação e salienta o importante papel dos órgãos de monitoramento do sistema interamericano de direitos humanos no sentido de evitar que prevaleça interpretação em tal sentido.
} 
liberdade de expressão é pedra angular das sociedades democráticas (§ 69), confirmar o seu caráter individual e social $(\S 71)$ e reconhecer a aplicabilidade do art. 13 da Convenção Americana sobre Direitos Humanos (1969) às relações digitais (§§ 81-83), o relator mostrou especial preocupação com as ordens judiciais de exclusão de conteúdos na internet proferidas no continente americano ${ }^{122}$. Nas suas palavras, apenas postagens estritamente ilícitas, tais como propagandas de guerra, discursos de apologia à violência e incitamento direto e público ao genocídio e pornografia infantil podem ser objetos de bloqueio e filtros no meio digital.

Observa-se dos documentos pesquisados (parecer consultivo, sentenças e relatórios temáticos) que o caso brasileiro não se encaixa nos parâmetros referendados pelos órgãos de monitoramento do sistema interamericano de direitos humanos capazes de justificar a restrição à liberdade de expressão. Isso porque, ao assim agir, o Poder Judiciário fluminense $^{123}$ : i) agrediu o direito fundamental individual do grupo humorístico em fazer circular sua criação artística valorativa sobre uma obra que, embora tida como sacra, não se baseia em fatos da realidade; ii) violou a liberdade de expressão em seu aspecto social, haja

\footnotetext{
${ }^{122}$ Cf. parte do teor do relatório: "§ 86. The Office of the Special Rapporteur has observed with concern how some countries in the region have been resorting to the blocking of specific websites or applications for different reasons - and even with a judicial order, with little or no regard to the implications of such measures on the right to freedom of expression online. § 87. The Joint Declaration on Freedom of Expression and the Internet, states that forcing the blocking or suspension of entire websites, platforms, channels, IP addresses, domain name extensions, ports, network protocols, or any other kind of application, as well as measures intended to eliminate links, information and websites from the servers on which they are stored, all constitute restrictions that are prohibited and exceptionally admissible only strictly pursuant to the terms of article 13 of the American Convention. The Joint Declaration on Freedom of Expression and 'Fake News', Disinformation and Propaganda indicates that these measures 'can only be justified where it is provided by law and is necessary to protect a human right or other legitimate public interest, including in the sense of that it is proportionate, there are no less intrusive alternative measures which would protect the interest and it respects minimum due process guarantees.' § 88. The Office of the Special Rapporteur has indicated that '[i]n exceptional cases of clearly illegal content or speech that is not covered by the right to freedom of expression (such as war propaganda and hate speech inciting violence, direct and public incitement to genocide, and child pornography) the adoption of mandatory measures to block and filter specific content is admissible. In these cases, the measure must be subjected to a strict balance of proportionality and be carefully designed and clearly limited so as to not affect legitimate speech that deserves protection. In other words, filtration or blocking should be designed and applied so as to exclusively impact the illegal content without affecting other content. The measures must be authorized or put in place pursuant to the appropriate procedural guarantees, in the terms of articles 8 and 25 of the American Convention. In this regard, the measures should only be adopted after the illegal content to be blocked has been fully and clearly identified, and when necessary to achieve a pressing aim. In any case, these measures must not be applied to legal content.' § 89. Restrictive measures should at all times include safeguards to prevent abuse, such as transparency with regard to the content whose removal has been ordered, as well as detailed information regarding the measures' necessity and justification. At the same time, a measure of this kind should be adopted only when it is the only measure available for achieving an imperative end and is strictly tailored to achieve it."

${ }^{123} \mathrm{~A}$ isso tudo é possível adicionar que o Judiciário estadual se afastou do seu dever de atuar com laicidade, uma vez que uma das suas principais argumentações para o deferimento da medida cautelar é o fato de a sociedade brasileira ser "majoritariamente cristã". A justificativa desafia a letra do art. 19, I, da Constituição Federal de 1988. Este elemento não foi objeto de consideração neste trabalho porque não foi suscitado pelo sistema interamericano de direitos humanos nos documentos analisados.
} 
vista ter impedido que vários brasileiros pudessem ter acesso ao conteúdo disponibilizado na plataforma de streaming e elaborar o seu próprio juízo valorativo; iii) a medida adotada não foi a estritamente necessária, uma vez casos de eventuais ofensas a direitos de terceiros pelo uso da liberdade de expressão devem ser resolvidas posteriormente, de preferência no campo da responsabilidade civil; e iv) o conteúdo elaborado pelo Porta dos Fundos não corresponde a quaisquer das hipóteses que a Convenção Americana sobre Direitos Humanos (1969) taxativamente autoriza a possibilidade de tolhimento da liberdade de expressão ${ }^{124}$.

Embora a decisão do Desembargador Benedicto Abicair tenha sido cassada pelo STF, é importante apontar sua incompatibilidade com os parâmetros protetivos em direitos humanos para evitar o uso abusivo, retórico e estratégico dos tratados e da jurisprudência internacional, como aparentemente se quis fazer na decisão monocrática estadual. A liberdade de expressão, na forma concebida pela Convenção Americana de Direitos Humanos (1969) e compreendida pelos órgãos de monitoramento, impunha ao caso do Porta dos Fundos e da Netflix um tratamento diverso do que lhes foi endereçado em segundo grau de jurisdição.

\section{Conclusão}

O direito à liberdade de expressão foi tradicionalmente positivado como fundamental no constitucionalismo brasileiro. A proteção dessa prerrogativa é inerente à formação e manutenção de um Estado Democrático, daí o seu duplo valor intrínseco e instrumental. No mesmo passo, diversos tratados de direitos humanos estabelecem igual importância a esta categoria jurídica, a exemplo dos documentos firmados nos âmbitos da ONU, da OEA e de outras entidades intergovernamentais.

Com o advento da internet e o surgimento de ferramentas que cada vez mais facilitam a produção de conteúdo dos mais variados matizes, nada mais natural que discursos vistos como indesejáveis por alguns setores da população sejam mais comumente divulgados. É dentro dessa órbita que se insere o humor, especialmente as produções caracterizadas por maior acidez. O caso do Porta dos Fundos é emblemático neste sentido, pois o grupo elaborou uma sátira envolvendo personagens religiosos tidos como sagrados por ampla parcela da população brasileira. Esta conjuntura causou insatisfações que culminaram no acionamento da máquina jurisdicional do Estado a fim de impedir a divulgação da obra audiovisual.

${ }^{124}$ Cf. art. 13(5) da Convenção Americana sobre Direitos Humanos (1969). 
A decisão monocrática tomada pelo desembargador do TJRJ, supostamente embasada com o objetivo de "acalmar os ânimos" de uma sociedade "majoritariamente cristã", desafiou os conteúdos de proteção à liberdade de expressão adotados tanto no direito constitucional quanto no direito internacional dos direitos humanos. No aspecto doméstico, rapidamente ela foi cassada pela Presidência do Supremo Tribunal Federal a partir de reclamação veiculada pelas empresas afetadas. A leitura da Constituição feita tradicionalmente pelo órgão quanto à matéria em discussão desautoriza o estabelecimento de censura a manifestações artísticas, como apontado pelo Min. Dias Toffoli.

O caso é mais grave, todavia, no direito internacional. A despeito de o desembargador relator ter dito que sustentou sua fundamentação em decisões das Cortes Europeia e Internacional (SIC) de Direitos Humanos, a pesquisa ora empreendida mostra resultado contrário. O teor do art. 13 da Convenção Americana de Direitos Humanos (1969), mormente quando associado às leituras lhe atribuídas pela Comissão e pela Corte Interamericanas de Direitos Humanos em suas jurisprudências evolutivas, impõe graves impedimentos à restrição de conteúdos veiculados por meio da liberdade de expressão, inclusive na internet. Segundo tal norma e os seus principais órgãos de monitoramento, insatisfações quanto ao exercício da liberdade de expressão, assim como dito pelo STF, devem ser preferencialmente resolvidos no campo da responsabilidade civil por meio de medidas posteriores. O tolhimento da veiculação de mensagens, sejam políticas, artísticas, científicas etc. constitui uma afronta a direitos individuais e sociais, dado o binômio que caracteriza os aspectos da liberdade de expressão.

O conteúdo audiovisual veiculado pelo Porta dos Fundos e pela Netflix não constitui propaganda de guerra, apologia à violência, incitamento ao genocídio ou pornografia infantil. Assim sendo, não há justificativa, no sistema interamericano, para a sua censura. Como o Brasil voluntariamente aquiesceu ao cumprimento das garantias de direitos humanos ofertadas por esta instância regional, seus parâmetros protetivos devem ser levados a sério pela jurisdição doméstica, algo não tomado em consideração pelo Judiciário fluminense na situação analisada.

\section{Referências}

ABBOTT, Max Silva. El Incierto Futuro de la Libertad de Expresión en el Sistema Interamericano de Derechos Humanos. Revista Chilena de Derecho, vol. 42, n. 03, 2015, pp. 
1063-1096. Disponível em: https://scielo.conicyt.cl/pdf/rchilder/v42n3/art13.pdf. Acesso em: 22 jan. 2020.

AGUIAR, Marcus Pinto. Liberdade de Expressão e a Busca da Igualdade na Sociedade Plural. Revista do Instituto Brasileiro de Direitos Humanos, vol. 13, n. 13, 2013, pp. 237-248. Disponível em: http://revista.ibdh.org.br/index.php/ibdh/article/view/247. Acesso em: 22 jan. 2020.

BRASIL. Constituição (1824). Constituição Política do Império do Brazil. Rio de Janeiro, DF, abr. 1824.

BRASIL. Constituição (1891). Constituição da República dos Estados Unidos do Brasil (de 24 de fevereiro de 1891). Rio de Janeiro, DF, fev. 1891.

BRASIL. Constituição (1934). Constituição da República dos Estados Unidos do Brasil (de 16 de julho de 1934). Rio de Janeiro, DF, jul. 1934.

BRASIL. Constituição (1937). Constituição dos Estados Unidos do Brasil (de 10 de novembro de 1937). Rio de Janeiro, DF, nov. 1937.

BRASIL. Constituição (1946). Constituição dos Estados Unidos do Brasil (de 18 de setembro de 1946). Rio de Janeiro, DF, set. 1946.

BRASIL. Constituição (1967). Constituição da República Federativa do Brasil de 1967. Brasília, DF, jan. 1967.

BRASIL. Constituição (1988). Constituição da República Federativa do Brasil de 1988. Brasília, DF, out. 1988.

BRASIL. Decreto n. 4.463, de 08 de novembro de 2002. Promulga a Declaração de Reconhecimento da Competência Obrigatória da Corte Interamericana de Direitos Humanos, sob reserva de reciprocidade, em consonância com o art. 62 da Convenção Americana sobre Direitos Humanos (Pacto de São José), de 22 de novembro de 1969. Brasília, DF, nov. 2002.

BRASIL. Decreto n. 592, de 06 de julho de 1992. Atos Internacionais. Pacto Internacional sobre Direitos Civis e Políticos. Promulgação. Brasília, DF, jul. 1992.

BRASIL. Decreto n. 678, de 06 de novembro de 1992. Promulga a Convenção Americana sobre Direitos Humanos (Pacto de São José da Costa Rica), de 22 de novembro de 1969. Brasília, DF, nov. 1992.

BRASIL. Lei n. 12.965, de 23 de abril de 2014. Estabelece princípios, garantias, direitos e deveres para o uso da Internet no Brasil. Brasília, DF, abr. 2014.

BRASIL. Supremo Tribunal Federal. Medida Cautelar na Reclamação n. 38.782/RJ, Rel. Min. Gilmar Ferreira Mendes, Decisão Monocrática do Min. Dias Toffoli. Disponível em: https://www.conjur.com.br/dl/toffoli-concede-liminar-suspende.pdf. Acesso em: 16 jan. 2020. 
BRASIL. Tribunal de Justiça do Rio de Janeiro. Agravo de Instrumento n. 008389672.2019.8.19.0000, Sexta Câmara Cível, Rel. Des. Benedicto Abicair, Decisão Monocrática. Disponível em: https://www.conjur.com.br/dl/desembargador-tj-rj-censura-especial.pdf. Acesso em: 16 jan. 2020.

CONSULTOR JURÍDICO. Por Tiago Angelo. Censura ao Porta dos Fundos é "absurda" e "sem fundamento", dizem especialistas. 08 de jan. 2020, às 19h56. Disponível em: https://www.conjur.com.br/2020-jan-08/censura-porta-fundos-absurda-fundamento. Acesso em: 04 fev. 2020.

CORTE INTERAMERICANA DE DIREITOS HUMANOS. Caso "A Última Tentação de Cristo" (Olmedo Bustos e Outros) v. Chile. Mérito, Reparações e Custas. Julgamento de 05 de Fevereiro de 2001. Série C, n. 73. Disponível em:

http://www.corteidh.or.cr/docs/casos/articulos/seriec_73_por.pdf. Acesso em: 22 jan. 2020.

CORTE INTERAMERICANA DE DIREITOS HUMANOS. Caso Kimel v. Argentina. Mérito, Reparações e Custas. Julgamento de 02 de maio de 2008. Série C, n. 177. Disponível em: http://www.corteidh.or.cr/docs/casos/articulos/seriec_177_por.pdf. Acesso em: $07 \mathrm{fev}$. 2020.

CORTE INTERAMERICANA DE DIREITOS HUMANOS. Parecer Consultivo OC-5/85, de 13 de novembro de 1985. O Registro Profissional Obrigatório de Jornalistas (artigos 13 e 29 da Convenção Americana sobre Direitos humanos). Solicitado pelo Governo da Costa Rica. Série A, n. 05. Disponível em:

http://www.corteidh.or.cr/docs/opiniones/seriea_05_por.pdf. Acesso em: 27 jan. 2020.

FALSARELLA, Christiane Mina. A Liberdade de Expressão na Jurisprudência da Corte Interamericana de Direitos Humanos. Revista da Faculdade de Direito da UFMG, Belo Horizonte, n. 61, 2012, pp. 149-174. DOI: 10.12818/P.0304-2340.2012v61p149. Acesso em: 22 jan. 2020.

FOLHA DE SÃO PAULO. Por Ana Luiza Albuquerque e Anna Virgínia Balloussier. Justiça determina censura de especial de Natal do Porta dos Fundos para 'acalmar ânimos'. Para relator, suspensão é benéfica 'não só para a comunidade cristã, mas para a sociedade brasileira, majoritariamente cristã'. 08 jan. 2020, às 18h18. Disponível em: https://www1.folha.uol.com.br/ilustrada/2020/01/justica-determina-retirada-do-ar-deespecial-de-natal-do-porta-dos-fundos-para-acalmar-animos.shtml. Acesso em: 04 fev. 2020.

HERTIG RANDALL, Maya. Freedom of Expression in the Internet. Swiss Review of International and European Law, vol. 26, n. 02, 2016, pp. 235-253.

INTER-AMERICAN COMMISSION ON HUMAN RIGHTS. Office of the Special Rapporteur for Freedom of Expression (Catalina Botero Marino). Freedom of Expression and the Internet. OEA/Ser.L/V/II. CIDH/RELE/INF. 11/13. 31 December, 2013. Disponível em:

http://www.oas.org/en/iachr/expression/docs/reports/2014_04_08_Internet_ENG\%20_WEB.p df. Acesso em: 20 jan. 2020.

INTER-AMERICAN COMMISSION ON HUMAN RIGHTS. Office of the Special Rapporteur for Freedom of Expression of the Inter-American Commission on Human Rights 
(Edison Lanza). Standards for a Free, Open and Inclusive Internet. OEA/Ser.L/V/II. CIDH/RELE/INF.17/17. March 15, 2017. Disponível em: http://www.oas.org/en/iachr/expression/docs/publications/INTERNET_2016_ENG.pdf. Acesso em: 20 jan. 2020.

MACHADO, Natália Paes Leme. A "Plena” Liberdade de Expressão e os Direitos Humanos: análise da jurisprudência da Corte Interamericana de Direitos Humanos e o Julgamento da ADPF 130. Revista de Direito Internacional, vol. 10, n. 02, 2013, pp. 281-296. DOI: http://dx.doi.org/10.5102/rdi.v10i2.2639. Acesso em: 22 jan. 2020.

MAGALHÃES, Breno Baía. A Abertura das Constituições ao Direito Internacional dos Direitos Humanos: ensaio introdutório. REJUR - Revista Jurídica da UFERSA, vol. 01, n. 01, jan./jul. 2017, pp. 111-130. DOI: https://doi.org/10.21708/issn2526-9488.v1.n1.p111130.2017. Acesso em: 06 fev. 2020.

MUÑOZ, Asier Garrido. El Valor Jurídico de la Declaración Universal de los Derechos Humanos. In: PRONER, Carol; OLASOLO, Héctor; DURÁN, Carlos Villán; RICOBOM, Gisele; BACK, Charlotth. (Coords.). 70 Aniversario de la Declaración Universal de Derechos Humanos: la protección internacional de los derechos humanos en cuestión. Valencia: Tirant lo Blanch, pp. 99-101, 2018. Disponível em:

https://joaquinherreraflores.org/sites/default/files/ebook_70_aniversario_declaracion_universa 1_de_dd_hh.pdf. Acesso em: 30 ago. 2018.

OLIVA, Thiago Dias; ANTONIALLI, Dennys Marcelo; DOS SANTOS, Maike Wilke. Censura Judicial ao Humor: análise de decisões judiciais envolvendo liberdade de expressão na internet. Revista Direitos Culturais, Santo Ângelo, vol. 14, n. 34, set./dez. 2019, pp. 1944. DOI: http://dx.doi.org/10.20912/rdc.v14i34.2914. Acesso em: 22 jan. 2020.

ORGANIZAÇÃO DAS NAÇÕES UNIDAS. Declaração Universal dos Direitos Humanos. Adotada e proclamada pela resolução 217 A (III) da Assembleia Geral das Nações Unidas em 10 de dezembro de 1948. Nova York, NY, dez. 1948.

ORGANIZAÇÃO DOS ESTADOS AMERICANOS. Declaração Americana dos Direitos e Deveres do Homem. Aprovada na Nona Conferência Internacional Americana. Bogotá, 1948.

SOARES, Inês Virgínia Prado. Liberdade de Expressão Artística na Jurisdição Constitucional: a contribuição do Supremo Tribunal Federal para a gestão democrática da cultura. In: CUNHA FILHO, Francisco Humberto; COSTA, Rodrigo Vieira (orgs.). A Proteção da Liberdade de Expressão Artística: fundamentos e estudos de casos. Fortaleza: Gráfica LCR, 2019, pp. 69-90.

SOUZA; Carlos Affonso; LEMOS, Ronaldo; BOTTINO, Celina (coords.). Marco Civil da Internet: jurisprudência comentada. - São Paulo: Editora Revista dos Tribunais, 2017. 